\title{
Efficacy of 12-month treatment with the GH receptor antagonist pegvisomant in patients with acromegaly resistant to long-term, high-dose somatostatin analog treatment: effect on IGF-I levels, tumor mass, hypertension and glucose tolerance
}

Annamaria Colao, Rosario Pivonello, Renata S Auriemma, Maria Cristina De Martino, Martin Bidlingmaier ${ }^{1}$, Francesco Briganti ${ }^{2}$, Fabio Tortora ${ }^{2}$, Pia Burman ${ }^{3}$, Ione A Kourides ${ }^{3}$, Christian J Strasburger ${ }^{4}$ and Gaetano Lombardi

Department of Molecular and Clinical Endocrinology and Oncology, Section of Endocrinology, Federico II University of Naples, via S Pansini 5 , 80131 Naples, Italy, ${ }^{1}$ Neuroendocrine Unit Laboratories of Ludwig Maximilians University of Munich, Munich, Germany, ${ }^{2}$ Department of Neurological Sciences, Section of Neuroradiology, Federico II University of Naples, Naples, Italy, ${ }^{3}$ Pfizer Inc. 235 E 42 St. New York, NY 10017, USA, and ${ }^{4}$ Department of Endocrinology, Charité University Medicine, Charité Campus Mitte, Berlin, Germany

(Correspondence should be addressed to A Colao; Email: colao@unina.it)

\begin{abstract}
Objective: We aimed to investigate the efficacy of pegvisomant in patients with acromegaly resistant to long-term ( $\geqq 24$-month), high-dose treatment with octreotide-LAR ( $40 \mathrm{mg} / \mathrm{month}$ ) or lanreotide (120 mg/month).

Design: This was an open, prospective study.

Subjects and Methods: We studied 16 patients with acromegaly (nine women; aged 28-61 years). The main outcome measures were IGF-I levels, blood pressure, glucose tolerance and safety (liver function and tumor size). Pegvisomant was given at doses of $10-40 \mathrm{mg}$ s.c. daily. Dose titration was performed every month by IGF-I assay.

Results: Three patients spontaneously stopped pegvisomant treatment after 6-9 months because of poor compliance; from the measurement of serum pegvisomant, another patient was found not to inject herself properly. After 6 months, IGF-I levels decreased by $63 \pm 19 \%(767.8 \pm 152.9$ vs $299.8 \pm 162.9 \mu \mathrm{g} / \mathrm{l}, P<0.0001$, $t$-test); serum IGF-I levels normalized in 57\%. After 12 months, IGF-I levels normalized in nine $(75 \%)$ patients and were reduced by over $50 \%$ in another three $(25 \%)$. The mean tumor volume remained stable during the study (1198 \pm 1234 vs $\left.1196 \pm 1351 \mathrm{~mm}^{3}, P=0.37\right)$ : it did not change $( \pm 25 \%$ vs basal $)$ in nine patients, increased by $39.4 \%$ and $40.8 \%$ in two and decreased by $30.8-46.5 \%$ in four. The total/high-density lipoprotein (HDL):cholesterol ratio (from $4.4 \pm 1.0$ to $3.7 \pm 0.6, P=0.0012$ ), glucose levels (from $5.6 \pm 1.2$ to $4.4 \pm 1.4 \mathrm{mmol} / \mathrm{l}, P=0.026$ ), insulin levels (from $12.4 \pm 6.7$ to $8.1 \pm 3.0 \mathrm{mUl} / \mathrm{l}, P=0.0023$ ) and homeostasis model assessment (HOMA) index (from 3.4 \pm 2.1 to $1.9 \pm 1.0, P=0.0017$ ) decreased. Conclusions: Treatment for 12 months with pegvisomant normalized IGF-I levels, and improved cardiovascular risk parameters and insulin sensitivity in patients with acromegaly resistant to long-term, high-dose treatment with somatostatin analogs. The tolerance of treatment was good.
\end{abstract}

European Journal of Endocrinology $154467-477$

\section{Introduction}

The optimal treatment for acromegaly should remove the tumor while preserving normal residual pituitary function, restore normal growth hormone $(\mathrm{GH})$ and insulin-like growth factor (IGF)-I secretion, and relieve symptoms and complications directly caused by $\mathrm{GH}$ excess, ultimately reversing the unfavorable long-term outcome (1). Current treatment options include surgery, radiotherapy and pharmacotherapy with somatostatin analogs, dopamine agonists and, more recently, a genetically engineered GH-receptor antagonist, pegvisomant.

Trans-sphenoidal adenomectomy remains a cornerstone of treatment for $\mathrm{GH}-$ secreting tumors: however, even in the most experienced hands, surgery is successful in the majority of microadenomas and enclosed macroadenomas but fails in larger or invasive tumors that represent the majority of $\mathrm{GH}$-secreting tumors $(2-5)$. Radiotherapy, delivered by external radiation, proton beam, gamma particles and interstitial radiotherapy, 
should be reserved for patients in whom surgery is contraindicated or unsuccessful, and in whom medical treatment fails to control persistent hormone excess due to residual tumor (6). The occurrence of severe complications, such as cranial nerve palsies, optic neuritis, impaired memory, lethargy and tissue necrosis, has decreased with modern techniques, but damage of the normal hypothalamic-pituitary region results in hypopituitarism in more than half of the patients within 10 years $(1,6,7)$.

Dopamine agonists are less effective than somatostatin analogs in normalizing GH and IGF-I excess: disease control is more likely achieved in patients with mixed prolactin/GH-secreting adenomas than in those with pure GH-secreting adenomas, and in patients with lower GH and IGF-I levels before treatment (1). Currently, somatostatin analogs, especially the longacting formulations, octreotide-LAR and lanreotide, are the most widely used drugs to control acromegaly. Serum IGF-I levels normalize in two-thirds of selected patients (8-13), and tumor shrinkage $(>20 \%)$ occurs in most $(>70 \%)$ de novo patients (14-16). Indeed, a recent meta-analysis of the literature reported that, for patients who experienced significant shrinkage, an approximately 50\% decrease in pituitary mass is achieved when a somatostatin analog is used exclusively or before surgery or radiotherapy (17). Thus, one-third of patients are not controlled by currently available treatments.

Blocking the activity of the GH receptor by pegvisomant, thereby inhibiting the synthesis of IGF-I, is a new pharmacologic approach to acromegaly. A placebo-controlled, 12-week study found a significant dose-dependent fall in serum IGF-I after pegvisomant compared with placebo, and $89 \%$ of the patients treated with $20 \mathrm{mg}$ normalized IGF-I levels (18). In another study, $97 \%$ of 186 patients treated for at least 12 months normalized IGF-I levels (19). There are only two reports on the efficacy of pegvisomant, in six and seven patients respectively, with acromegaly resistant to somatostatin analogs $(20,21)$. Normalized IGF-I levels were found in all patients after 6-12 weeks and 12-24 months respectively. The results, however, were limited to IGF-I levels in both studies.

Here we present our preliminary experience in 16 patients with acromegaly who previously had undergone unsuccessful surgery and/or radiotherapy and were shown to be resistant to long-term, high-dose treatment with octreotide-LAR or lanreotide.

\section{Patients and methods}

\section{Inclusion criteria}

This open-label, 12-month study included patients 18 years of age or older with previously established diagnosis of acromegaly (GH nadir during oral glucose tolerance test (oGTT) of $>1 \mu \mathrm{g} / \mathrm{l})$. IGF-I levels had to be at least 1.3 times above the upper limit of normal ageand sex-matched controls, after a 4-month washout of long-acting somatostatin analogs. The patients were required to have had stable hormone replacement therapy for hypopituitarism for at least 6 months prior to study start and stable size of the pituitary tumor (shown by magnetic resonance imaging (MRI)) for the last 12 months. Patients were excluded from the study if they had had treatment with dopamine agonists during the 5 weeks prior to study start, a pituitary adenoma with a distance to the optic chiasm of $3 \mathrm{~mm}$ or less, chronic hepatitis, known or suspected drug/ alcohol abuse, or any other condition (such as severe hepatic or renal disease, or malnutrition) that could result in abnormal GH or IGF-I concentrations, history of relevant drug or food allergies, or unwillingness or inability to self-administer the study medication. All women of childbearing age were required to use an acceptable form of contraception throughout the study. Women who were pregnant or nursing were excluded from participation. The ethics committee of the University Federico II of Naples approved the protocol, and all patients provided written, informed consent prior to study participation.

\section{Patients}

Sixteen patients (nine women, seven men, age range 28-61 years, median 46.5 years) were enrolled. All patients but two had previously undergone surgery and two patients had also received radiotherapy (patient no. 10 for 3 years and no. 16 for 12 years before entering the study; Table 1). All patients had been treated with octreotide-LAR or lanreotide (LAN) at the maximal tolerated dose (LAR $40 \mathrm{mg} / \mathrm{month}$, LAN $120 \mathrm{mg} / \mathrm{month}$ ) for at least 24 months (24-60 months, median 38 months) without achieving disease control. Patient profiles are shown in Table 1. Hypertension was diagnosed when diastolic blood pressure (DBP) values were over $90 \mathrm{mmHg}$ and was graded as mild at 91-104 $\mathrm{mmHg}$, moderate at 105-114 mmHg, and severe at $\geq 115 \mathrm{mmHg}$, in line with WHO criteria (22). Among the 16 patients, four (25\%) had hypertension; this was mild in three patients and severe in one. Hypertension was treated with combination therapy of an angiotensin receptor antagonist and a diuretic. Only the patient with severe hypertension was also treated with beta-blockers. Five patients $(31.2 \%)$ had diabetes mellitus (defined as fasting glucose of $>7 \mathrm{mmol} / \mathrm{l}$ on two consecutive measurements or 2-h glucose during oGTT of $>11.1 \mathrm{mmol} / \mathrm{l})$ : during the previous treatment with somatostatin analogs, diabetes was treated with insulin in two patients and insulin sensitizers in the remaining three. However, before starting pegvisomant, the treatment of diabetes was withdrawn, and patients received only a low-calorie, low-carbohydrate diet. One patient $(6.2 \%)$ had glucose intolerance (defined as 2-h glucose of 7-11.1 during oGTT with an additional value over 
Table 1 Patient profiles at study entry and effects of pegvisomant treatment.

\begin{tabular}{|c|c|c|c|c|c|c|c|c|c|c|c|c|c|c|}
\hline \multirow[b]{2}{*}{$\begin{array}{l}\text { Patient } \\
\text { no. }\end{array}$} & & \multirow[b]{2}{*}{$\begin{array}{l}\text { Age } \\
\text { (years) }\end{array}$} & \multicolumn{2}{|c|}{$\begin{array}{l}\text { Serum GH } \\
\text { levels }\end{array}$} & \multicolumn{2}{|c|}{$\begin{array}{c}\text { Serum IGF-I } \\
\text { levels }\end{array}$} & \multirow[b]{2}{*}{ Tumor description } & \multicolumn{3}{|c|}{$\begin{array}{l}\text { MRI findings } \\
\text { Tumor volume }\end{array}$} & \multicolumn{4}{|c|}{ Pegvisomant treatment } \\
\hline & & & $\begin{array}{l}\text { Before } \\
(\mu \mathrm{g} / \mathrm{l})\end{array}$ & After & $\begin{array}{l}\text { Before } \\
(\mu \mathrm{g} / \mathrm{l})\end{array}$ & After & & $\begin{array}{l}\text { Before } \\
\left(\mathrm{mm}^{3}\right)\end{array}$ & $\begin{array}{l}\text { After } \\
\left(\mathrm{mm}^{3}\right)\end{array}$ & $\begin{array}{c}\Delta \text { Change } \\
(\%)\end{array}$ & $\begin{array}{l}\text { Dose } \\
\text { (mg/day) }\end{array}$ & $\begin{array}{l}\text { Blood levels } \\
(\mu \mathrm{g} / \mathrm{l})\end{array}$ & $\begin{array}{l}\text { Duration } \\
\text { (months) }\end{array}$ & Side effects \\
\hline 1. & M & 28 & 9.0 & 17.8 & 898 & 267 & remnant at r-CS, partial empty sella & 364 & 291.2 & -20.0 & 25 & 40960 & 12 & \\
\hline 2. & M & 29 & 3.4 & 14.3 & 748 & 222 & remnant at I-CS & 182 & 171.6 & -5.7 & 25 & 40600 & 12 & $\uparrow$ Transaminases \\
\hline 3. & M & 32 & 14.4 & 66.8 & 756 & 279 & residual macro I, r-P & 936 & 1318.2 & 40.8 & 15 & 36560 & 12 & $\uparrow$ Tumor size \\
\hline 4. & $\mathrm{~F}$ & 35 & 5.6 & 14.4 & 594 & 180 & negative & 49.9 & 49.9 & 0.0 & 10 & 42240 & 12 & \\
\hline 5. & $\mathrm{~F}$ & 39 & 71.2 & 95.7 & 834 & 467 & residual macro I, r-P & 2995.2 & 2784.6 & -7.0 & 40 & 45200 & 12 & \\
\hline 6. & M & 42 & 74.8 & 145 & 870 & 297 & residual macro I, S, bilateral P & 2386.8 & 3328 & 39.4 & 35 & 77280 & 12 & $\uparrow$ Tumor size \\
\hline 7. & $\mathrm{~F}$ & 44 & 4.5 & 6.3 & 525 & 117 & remnant at r-CS, partial empty sella & 262.1 & 145.6 & -44.4 & 15 & 34930 & 12 & \\
\hline 8. & $\mathrm{~F}$ & 46 & 18.1 & 18.1 & 728 & 137 & remnant at r-CS, partial empty sella & 686.4 & 520 & -24.2 & 15 & 11340 & 12 & \\
\hline 9. & $\mathrm{~F}^{\mathrm{E}}$ & 47 & 32.9 & 15.3 & 828 & 792 & residual macro S, I-P & 2652 & 2652 & 0.0 & 40 & 50 & 12 & \\
\hline 10. & $F_{* *}$ & 49 & 48.5 & 31.5 & 638 & 166 & remnant at r-CS, partial empty sella & 1081.6 & 748.8 & -30.8 & 25 & 41240 & 12 & \\
\hline 11. & $M^{*}$ & 52 & 9.3 & 7.7 & 900 & 195 & remnant posterior, partial empty sella & 1123.2 & 1123.2 & -33.3 & 30 & 49760 & 12 & \\
\hline 12. & $M^{*}$ & 52 & 21.9 & 19.9 & 1023 & 353 & negative & 823.7 & 440.4 & -46.5 & 40 & 11780 & 9 & \\
\hline 13. & $\mathrm{~F}$ & 55 & 17.2 & 20 & 729 & 113 & residual macro I, r-P & 520 & 468 & -10.0 & 20 & 34400 & 12 & \\
\hline 14. & $\mathrm{~F}^{\mathrm{E}}$ & 56 & 13.4 & 13 & 937 & 291 & remnant at r-CS & 218.4 & 218.4 & 0.0 & 10 & 5680 & 6 & $\uparrow$ Transaminases \\
\hline 15. & $\mathrm{~F}$ & 58 & 8.4 & 11 & 674 & 124 & empty sella & & & & 25 & 37800 & 12 & \\
\hline 16. & $M^{\star *}$ & 61 & 15 & 15 & 935 & 252 & residual macro i, I-P & 4160 & 4160 & 0.0 & 25 & 21640 & 6 & \\
\hline
\end{tabular}

*Patients treated with somatostatin analogs only. **|rradiated patients. CS: cavernous sinus; S: suprasellar; I: intrasellar; P: parasellar; i: infrasellar; r: right; I: left; superscript E: patients excluded from the analysis because the pegvisomant dose was not appropriate. Patient 9 was excluded because did not inject herself appropriately and patient 14 because of stably increased transaminases. 
$11.1 \mathrm{mmol} / \mathrm{l}$ at $0-2 \mathrm{~h}$ after oGTT) (23) and did not receive any specific treatment.

\section{Study design}

After an initial loading dose of $40 \mathrm{mg}$ pegvisomant, treatment was started with $10 \mathrm{mg} /$ day s.c. The dose was adjusted $( \pm 5 \mathrm{mg})$ every 6 weeks by IGF-I levels obtained 2 weeks before the time for dose adjustment. The goal was to obtain an IGF-I concentration within the normal range for sex and age; however, the pegvisomant dose was not to be above $40 \mathrm{mg}$ or below $5 \mathrm{mg}$. In one patient, titration of the dose was not possible due to increase of liver transaminase levels: this patient (no. 14, Table 1) was excluded from the calculation of treatment efficacy. Another patient (no. 9) did not inject herself properly as demonstrated by the blood levels of pegvisomant assayed at study end: this patient was also excluded from the calculation of treatment efficacy. The maximal dose of pegvisomant was $10 \mathrm{mg}$ in two patients, $15 \mathrm{mg}$ in three, $20 \mathrm{mg}$ in one, $25 \mathrm{mg}$ in five, $30 \mathrm{mg}$ in one, $35 \mathrm{mg}$ in one and $40 \mathrm{mg}$ in the remaining three patients (Table 1). Vital signs and adverse events were monitored at each study visit (every 6 weeks) until the 6-month visit and then every 12 weeks. Blood pressure was measured in the right arm, with the subjects in a relaxed sitting position; the average of six measurements (three taken by each of two examiners) with a mercury sphygmomanometer was taken. Moreover, change in ring size of the fourth digit of the right hand (fifth digit if the fourth was too large) was measured by a jeweler's ring-sizing system over the course of the study. Laboratory assessments, including fasting glucose, fasting insulin, GH (calculated as the mean of a 6 -h blood sampling, 0800-1400 h, with 30-min sampling), serum triglycerides, total cholesterol, HDL-cholesterol and fibrinogen, were conducted at baseline and at the 6- and 12-month visits. Blood for liver chemistry tests (alanine aminotransferase (ALT), aspartate transaminase (AST) and albumin) and for routine laboratory tests (hematology and serum chemistry) was collected every 4 weeks. The total/ high-density lipoprotein (HDL)-cholesterol ratio, considered an index of severe cardiovascular risk (24), and the estimate of insulin resistance by homeostasis model assessment (HOMA) score, by applying the Matthews et al. formula (25) (fasting serum insulin $(\mu \mathrm{U} / \mathrm{ml}) \times$ fasting plasma glucose $(\mathrm{mmol} / \mathrm{l}) / 22.5)$, were also calculated. The conversion factors $(\mathrm{mg} / \mathrm{dl}$ to $\mathrm{mmol} / \mathrm{l})$ for lipids and glucose were as follows: cholesterol 0.02586 , triglycerides 0.01129 and glucose 0.05551 .

\section{MRI studies}

MRI studies were performed on clinical $0.5 \mathrm{~T}, 1 \mathrm{~T}$ and $1.5 \mathrm{~T}$ scanners, using $\mathrm{T} 1$-weighted gradient recalled-echo (repetition time $200-300 \mathrm{~ms}$; echo time
10-12 ms; flip angle $90^{\circ}$, four signal averages) in the sagittal and coronal planes, as already reported (15). In each measurement, 7-11 slices were obtained, with a slice thickness of $2-3 \mathrm{~mm}$ and an in-plane spatial resolution of $0.7-0.97 \mathrm{~mm}$ (the matrix was $192-256 \times 256$ on a field of view of $24-25 \mathrm{~cm}$ on the sagittal plane, and $160-256 \times 256$ on a field of view of $18-20 \mathrm{~cm}$ in the coronal plane). The acquisitions were repeated before and after the administration of $0.1 \mathrm{mmol}$ gadolinium chelate (diethylenetriamine pentacetate). A pituitary MRI and a visual perimetry were performed at screening $(-2$ to -4 weeks prior to start with pegvisomant) and at the 6and 12-month visits. Shrinkage was established on tumor volume calculated by the Di Chiro and Nelson formula $\quad($ volume $=$ height $\times$ length $\times$ width $\times \pi / 6)$ and on the maximal tumor diameter. Tumor shrinkage was semiquantitatively evaluated as change of the pretreatment tumor volume: $\pm 25 \%$ absent, $\pm 25-50 \%$ mild, and $\pm 50 \%$ notable (15). The radiologists (F B and F T) were blind to the status of the patients.

\section{Assays}

At diagnosis and during therapy with somatostatin analogs, serum GH levels were measured by IRMA (HGH-CTK-IRMA; Sorin, Saluggia, Italy); assay sensitivity was $0.2 \mu \mathrm{g} / \mathrm{l}$; the intra- and interassay coefficients of variation (CV) were $4.5 \%$ and $7.9 \%$ respectively. Before and during pegvisomant treatment, IGF-I assays were performed at the Neuroendocrine Unit Laboratories, Ludwig Maximilians University of Munich. Serum samples were shipped frozen on dry ice. Before analysis, samples were thawed and allowed to reach ambient temperature. IGF-I levels were measured by the automated Advantage chemiluminescent IGF-I assay system (Nichols Diagnostics Institute, Bad Nauheim, Germany). By this method, samples are acidified to separate IGF-I from its binding protein IGFBP-3. To prevent reassociation of IGF-I and IGFBPs, and thus to exclude interference of IGFBP-3, the acidified samples are incubated with an excess of IGF-II. The intra-assay CV were $11.5 \%, 5.1 \%$ and $3.5 \%$ at concentrations of 42,262 and $522 \mathrm{ng} / \mathrm{ml}$ respectively. At the same concentrations, betweenassay CV were $10.6 \%, 10.6 \%$ and $10.2 \%$. The lower limit of quantification was $17 \mathrm{ng} / \mathrm{ml}$, and the linear range was $17-1000 \mathrm{ng} / \mathrm{ml}$. Assays were performed in a central laboratory (Ludwig Maximilians University of Munich) where the researcher (M B) was blind to patients' response to previous treatments. Results were reported together with the assay-specific sex- and age-matched reference range (26).

In order to monitor endogenous human (h) GH secretion in patients treated with the hGH-analog pegvisomant, a specific assay was designed to be free of interference by the drug. From a panel of monoclonal antibodies (mAbs) raised against $\mathrm{hGH}$, a pair of 
antibodies was identified, targeting epitopes in receptorbinding sites 1 and 2 respectively, which have been mutated in the hGH analog. Neither of the mAbs selected showed cross-reaction with pegvisomant, indicating that they target amino-acid residues mutated in pegvisomant. Combining these mAbs (8B11 and 6C1) in a sandwich assay leads to a linear dose-relationship for hGH with a lower detection limit of $0.2 \mathrm{ng} / \mathrm{ml}$ and an upper end of the linear working range at $50 \mathrm{ng} / \mathrm{ml}$ for $50 \mu \mathrm{l}$ samples. WHO IRP 80/505 is used as the calibrator. Intra-assay variabilities were $4.1 \%$ and $3.9 \%$ at concentrations of 5.2 and $14.6 \mu \mathrm{g} / \mathrm{l}$ respectively. Interassay variabilities at the same concentrations were determined to be $7.3 \%$ and $9.2 \%$ respectively (27). Serum concentrations of pegvisomant were determined by an immunofluorometric sandwich assay involving two mAbs, $10 \mathrm{~A} 7$ and $6 \mathrm{~F} 1$, raised against hGH and retaining high cross-reactivity with pegvisomant (25-50\% compared with recombinant human (rh)GH). The assay was calibrated against pegvisomant (Pfizer, New York, NY, USA) diluted in assay buffer. Serum concentrations of pegvisomant in treated patients are at least 500 higher than endogenous hGH concentrations. Therefore, all serum samples were diluted 1:100 in assay buffer prior to analysis to eliminate the interference from the endogenous hGH levels present in the samples. The assay has a linear working range of $0.5-200 \mathrm{ng} / \mathrm{ml}$, corresponding to final concentrations of 50-20000 ng/ml. Samples above $200 \mathrm{ng} / \mathrm{ml}$ have been diluted in assay buffer; samples below $0.5 \mathrm{ng} / \mathrm{ml}$ (corresponding to a final concentration of $50 \mathrm{ng} / \mathrm{ml}$ ) have been reported as ' $<50 \mathrm{ng} / \mathrm{ml}$ '. The within-assay variabilities were $7.5 \%, 4.6 \%$ and $5.2 \%$ at concentrations of 160,650 and $3900 \mathrm{ng} / \mathrm{ml}$ respectively. The between-assay variabilities were $13.5 \%, 6.4 \%$ and $8.5 \%$ at the same concentrations.

\section{Statistical analysis}

The statistical analysis was performed with the SPSS package (Cary, NC, USA). The effect of pegvisomant was analyzed by the Wilcoxon matched pair test (basal vs 6 or 12 months of treatment according to individual patient follow-up). The percent changes in IGF-I levels, GH levels and tumor volume were correlated with each other by calculating the Spearman correlation coefficient. Data are reported as mean+S.D. unless otherwise specified.

\section{Results}

\section{Serum IGF-I levels}

Of the initial 16 patients, two were withdrawn from treatment after 6 months because of inability to titrate the dose due to a rise of transaminase levels (no. 14 was positive for hepatitis $\mathrm{C}$ virus but had normal liver function at study entry) or inability to follow the protocol (no. 16); one patient (no. 12), although achieving normal IGF-I levels, was withdrawn from treatment after 9 months for poor compliance with the treatment and, at the completion of study, another patient (no. 9) was found not to inject herself properly by the results of pegvisomant assay $(830$ and $50 \mu \mathrm{g} / \mathrm{l}$, at 3 and 12 months of treatment, Table 1). While patients 12 and 16 were included in the analysis of the results, as they performed the treatment appropriately until withdrawal, the other two patients (nos. 9 and 14) were excluded. After 6-month pegvisomant treatment, IGFI levels decreased by $67 \pm 11 \%$. Serum IGF-I levels were in the normal range for age and gender in 8/14 patients $(57.1 \%)$ and were 1-1.3-fold above the upper normal range in another three patients $(20 \%)$. After 12 months, serum IGF-I levels were in the normal range in $9 / 12$ patients $(75 \%)$, and above the normal range but reduced by more than $50 \%$ of baseline in the remaining three $(25 \%)$. Serum GH levels did not significantly increase during treatment (Table 2).

\section{Tumor mass}

There was no significant change in residual tumor volume in $9 / 14$ patients $(64.3 \%$; Table 1$)$. In two patients, there was an increase of residual tumor mass; by 39\% in the former (no. 6, Table 1, Fig. 1) and $41 \%$ in the latter (patient no. 3, Table 1, Fig. 2). In neither of these patients was the increase in tumor volume associated with impairment of visual fields or other neurologic symptoms, except for mild headache in the latter patient. However, the former patient had rebound tumor growth after stopping octreotide-LAR therapy (Fig. 1). In both patients 3 and 6, GH levels increased significantly during treatment (from 14.4 to 66.8 and 74.8 to $108 \mu \mathrm{g} / \mathrm{l}$ respectively). In four patients $((28.6 \%)$ nos. 7 and $10-12$, Table 1$)$, there was a significant decrease of tumor mass of $30.8-46.5 \%$ respectively. One (no. 10, Table 1 ) of the four patients had undergone radiotherapy 30 months before study entry, while the other two patients did not receive radiotherapy. The percent changes in tumor volume did not correlate with the percent changes either in $\mathrm{GH}(r=0.32, P=0.26)$ or in IGF-I levels $(r=0.2 ; P=0.49)$.

\section{Hemodynamic and cardiovascular risk parameters (Table 2)}

At study entry, four patients had hypertension managed with angiotensin receptor inhibitors plus diuretics and/or beta-blockers with partial control of blood pressure. After pegvisomant treatment, there was no change of systolic and diastolic blood pressure, heart rate, fibrinogen, or total cholesterol and triglyceride levels in 


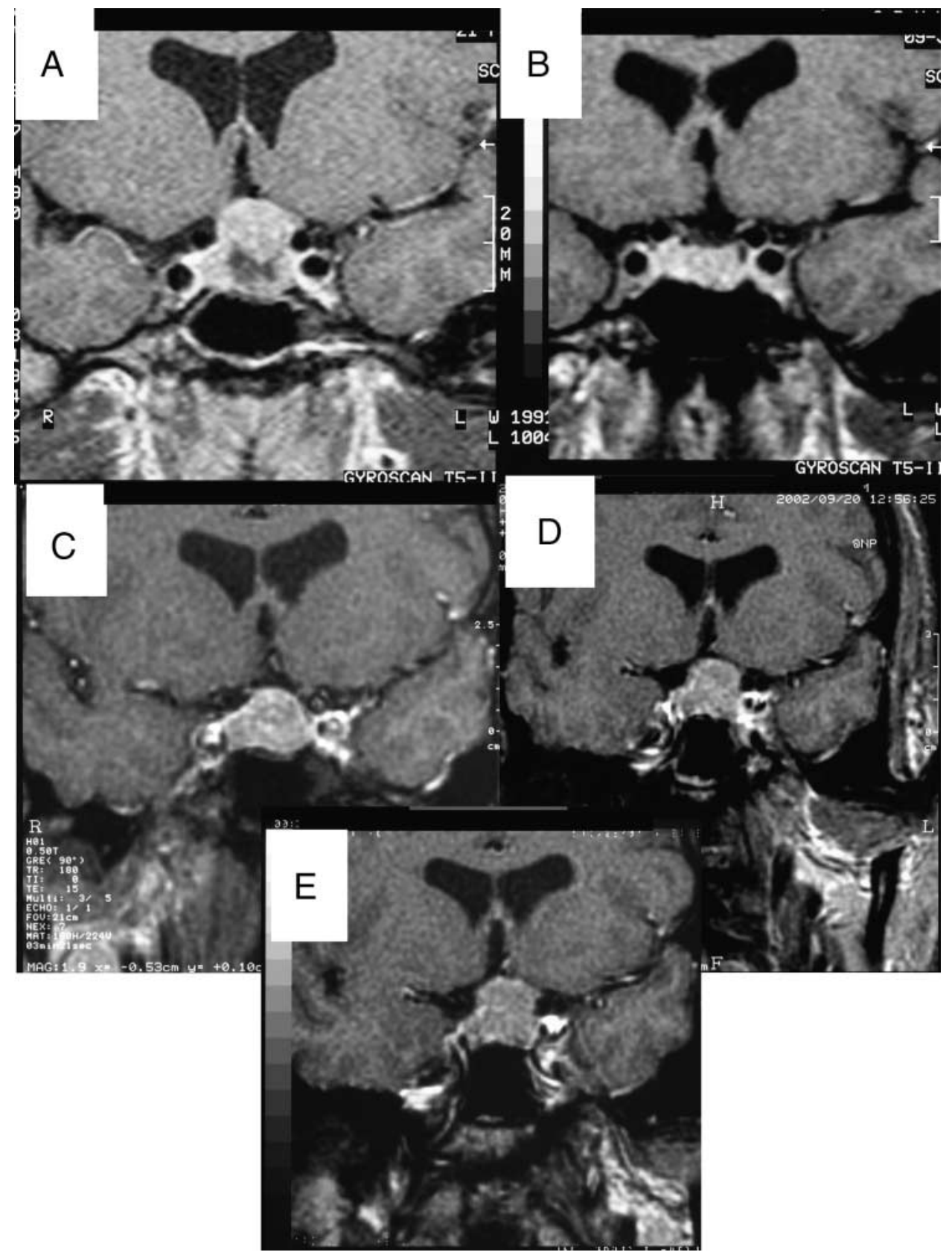

Figure 1 Coronal projections of sellar MRI before octreotide-LAR (A), after 24 months of octreotide-LAR at the dose of $40 \mathrm{mg} / \mathrm{month}$ $(B)$, and before (C) and after 6 (D) and 12 months of pegvisomant treatment (E) in patient no. 6 . Tumor increased by $39 \%$ compared with panel C. Tumor size increased by $56 \%$ after 4 months of octreotide-LAR withdrawal before starting pegvisomant treatment.

the entire series; HDL-cholesterol levels significantly increased, so that the total/HDL-cholesterol ratio significantly decreased. When hypertensive patients $(n=4)$ were considered separately from normotensive patients $(n=10)$, there was a significant decrease of diastolic blood pressure during treatment in those with hypertension (from 103.8 \pm 11.1 to $87.5 \pm 6.4 \mathrm{mmHg} ; \quad P=0.04)$; only one of the four patients remained hypertensive while doses of hypertensive drugs remained unchanged.

\section{Glucose tolerance and diabetes (Table 2)}

After pegvisomant treatment, in the entire series of patients, there was a significant decrease in glucose and insulin levels and HOMA index, without any significant change in glycosylated hemoglobin levels. In the six patients with diabetes or glucose intolerance, insulin levels (from $17.8 \pm 7.6$ to $8.9 \pm 3.6 \mathrm{mU} / \mathrm{l}$; $P=0.048$ ) and the HOMA index (from 5.3 \pm 2.4 to $2.0 \pm 0.9 ; \quad P=0.019)$ significantly decreased, while 


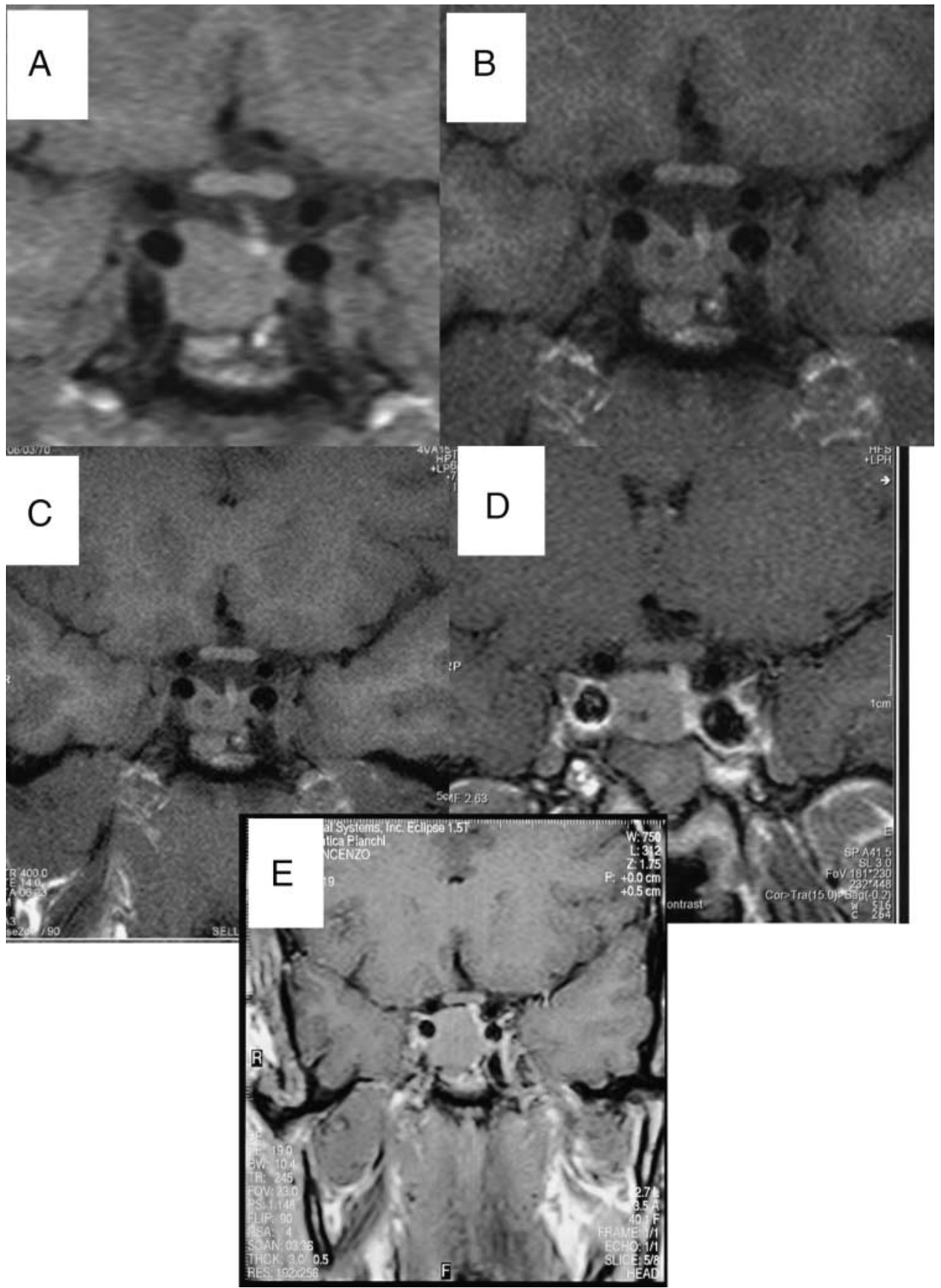

Figure 2 Coronal projections of sellar MRI before lanreotide (A), after 24 months of lanreotide at the dose of $120 \mathrm{mg} / \mathrm{month}(\mathrm{B})$, and before $(C)$ and after $6(D)$ and 12 months $(E)$ of pegvisomant treatment in patient no. 3. Tumor increased by $41 \%$ compared with panel C. Tumor size increased by $25 \%$ after 4 months of lanreotide withdrawal before starting pegvisomant treatment.

glucose levels also decreased (from $6.9 \pm 1.6$ to $5.0 \pm 0.1 \mathrm{mmol} / \mathrm{l} ; \mathrm{P}=0.08)$.

\section{Changes in symptom score (Table 3)}

None of the symptoms recorded significantly improved after treatment, although joint pain, asthenia, paresthesia and snoring showed a favorable trend.

\section{Tolerability of the treatment}

At the beginning of treatment, two patients had noted macroglossia that subsided with treatment. Two patients (nos. 2 and 14) had increases in liver transaminases, by 1.5- and 2-fold above the upper normal range after 2 months. Liver transaminases spontaneously normalized in one patient (no. 2) despite treatment continuation and increase of the dose. In the other 
Table 2 Effect of pegvisomant treatment on clinical, biochemical and endocrine findings. Data are shown as mean \pm S.D. and $P$ values refer to Wilcoxon matched $t$-test. The two patients noncompliant with treatment (nos 9 and 14 described in Table 1) were excluded from the calculation.

\begin{tabular}{|c|c|c|c|}
\hline & Before & After & $P$ \\
\hline Weight (kg) & $83.5 \pm 15.0$ & $85.7 \pm 13.6$ & 0.055 \\
\hline Serum GH levels $(\mu \mathrm{g} / \mathrm{l})$ & $22.9 \pm 24.0$ & $34.5 \pm 40.4$ & 0.29 \\
\hline Serum IGF-I levels ( $\mu \mathrm{g} / \mathrm{l})$ & $775.1 \pm 141.4$ & $237.8 \pm 106.7$ & $<0.0001$ \\
\hline Tumor volume $\left(\mathrm{mm}^{3}\right)$ & $1198 \pm 1234$ & $1196 \pm 1351$ & 0.37 \\
\hline Ring size $(\mathrm{mm})$ & $12.7 \pm 2.2$ & $12.2 \pm 2.3$ & 0.78 \\
\hline Systolic blood pressure (mmHg) & $133.9 \pm 16.2$ & $129.6 \pm 10.1$ & 0.13 \\
\hline Diastolic blood pressure $(\mathrm{mmHg})$ & $87.1 \pm 13.6$ & $86.2 \pm 7.1$ & 0.70 \\
\hline Heart rate (bpm) & $72.8 \pm 7.6$ & $76.8 \pm 7.9$ & 0.14 \\
\hline Total cholesterol levels (mmol/l) & $5.3 \pm 1.0$ & $5.5 \pm 0.8$ & 0.43 \\
\hline HDL-cholesterol levels (mmol/l) & $1.2 \pm 0.3$ & $1.5 \pm 0.2$ & 0.0017 \\
\hline Total/HDL-cholesterol ratio & $4.5 \pm 1.0$ & $3.7 \pm 0.6$ & 0.0012 \\
\hline Triglyceride levels $(\mathrm{mmol} / \mathrm{l})$ & $1.5 \pm 0.9$ & $1.5 \pm 0.7$ & 0.86 \\
\hline Glucose levels ( $\mathrm{mmol} / \mathrm{l})$ & $5.6 \pm 1.2$ & $4.4 \pm 1.4$ & 0.0012 \\
\hline HbA1c levels (\%) & $5.3 \pm 0.7$ & $5.3 \pm 0.5$ & 0.24 \\
\hline Insulin levels (mU/I) & $12.4 \pm 6.7$ & $8.1 \pm 3.0$ & 0.0023 \\
\hline HOMA index & $3.4 \pm 2.1$ & $1.9 \pm 1.0$ & 0.0017 \\
\hline Fibrinogen levels (mg/dl) & $342.1 \pm 75.2$ & $361.6 \pm 63.6$ & 0.58 \\
\hline AST levels (U/I) & $19.4 \pm 8.6$ & $22.9 \pm 15.1$ & 0.64 \\
\hline ALT levels (U/I) & $18.6 \pm 14.0$ & $40.1 \pm 61.2$ & 0.017 \\
\hline Albumin levels ( $\mathrm{g} / \mathrm{dl})$ & $3.8 \pm 0.4$ & $4.4 \pm 0.3$ & 0.0002 \\
\hline
\end{tabular}

patient (no. 14), the dose of pegvisomant was firstly increased from 10 to $15 \mathrm{mg}$ /day but was reduced again to $10 \mathrm{mg}$ /day because of a further and significant increase of transaminases levels accompanied by severe gastrointestinal discomfort. Only in this patient was the increase in transaminases levels accompanied by an increase in gamma-glutamyl transpeptidase $(\gamma$-GT) levels. Liver transaminases remained at the baseline level during the subsequent period of treatment that was stopped after the 6-month follow-up. Both patients were positive for hepatitis $C$ virus in the absence of overt hepatic disease at study entry. While AST levels did not change during the treatment, ALT levels significantly increased in the entire series (Table 2).

\section{Discussion}

The most important result of the current study is that after 12 months of treatment with the GH-receptor

Table 3 Effect of pegvisomant treatment on symptom score*. Data are shown as mean \pm S.D. and $P$ values refer to Wilcoxon matched $t$-test. The two patients noncompliant with treatment (nos 9 and 14 described in Table 1) were excluded from the calculation.

\begin{tabular}{lccc}
\hline & Before & After & $\boldsymbol{P}$ \\
\hline Headache & $2.6 \pm 1.9$ & $3.0 \pm 2.4$ & 0.59 \\
Sweating & $2.0 \pm 2.1$ & $1.6 \pm 2.2$ & 0.36 \\
Joint pain & $3.9 \pm 2.7$ & $2.8 \pm 2.6$ & 0.08 \\
Asthenia & $3.8 \pm 2.3$ & $2.6 \pm 2.6$ & 0.09 \\
Soft tissue swelling & $2.1 \pm 1.9$ & $2.1 \pm 1.8$ & 1.0 \\
Paresthesia & $3.0 \pm 2.7$ & $1.6 \pm 2.5$ & 0.08 \\
Snoring & $2.4 \pm 2.3$ & $1.5 \pm 1.9$ & 0.08 \\
\hline
\end{tabular}

*Disease signs and symptoms were scored on an 8-point scale from $0=$ absent to $8=$ severe, incapacitating antagonist, pegvisomant, normal IGF-I levels for age and sex were achieved in $11 / 14$ patients $(78.6 \%)$, and acromegaly was proven to be resistant to longterm, high-dose treatment with long-acting somatostatin analogs. In another three patients, IGF-I remained higher than normal but decreased by more than $50 \%$ of the baseline level. IGF-I normalization was accompanied by improved cardiovascular risk, that is, reduced total/HDL cholesterol ratio, and improved insulin sensitivity and blood pressure control. Additionally, there were no detrimental effects on tumor growth with the exception of two men who both had tumors with proven growth during the period of withdrawal from somatostatin analogs before entering the pegvisomant trial.

Even if data using pegvisomant in the treatment of acromegaly are still scant compared with those available with the somatostatin analogs, it is evident that this drug lowers serum IGF-I levels in patients with active acromegaly (27). Pegvisomant administration at daily doses of 10,15 or $20 \mathrm{mg}$ for 12 weeks induced a dose-dependent reduction of serum IGF-I, free IGF-I, insulin-like growth factor-binding protein (IGFBP)-3 and ALS in 112 patients with active acromegaly based on pretreatment IGF-I levels 1.3 times above the upper limit of an age-related reference range (18). Serum IGF-I levels within the age-adjusted reference range were achieved in $54 \%$ of the patients treated with $10 \mathrm{mg} /$ day, $81 \%$ in those treated with $15 \mathrm{mg}$ /day and $89 \%$ in those treated at $20 \mathrm{mg}$ /day (18). Besides, a significant reduction of symptoms and signs was recorded, including a reduction of ring size (18). Long-term follow-up of the patients included in previous clinical studies has indicated normalization of serum IGF-I levels in $97 \%$ of 186 patients treated for up to 18 months with doses up to $40 \mathrm{mg}$ 
(19). More recently, pegvisomant in weekly administrations was also shown to be very effective combined with somatostatin analogs in controling patients with active acromegaly (28).

However, all these studies were not designed to investigate the response to pegvisomant in patients with proven resistance to long-term, high-dose therapy with somatostatin analogs; these are the patients allowed to receive pegvisomant treatment in Europe according to the product label.

The only two studies $(20,21)$ reporting the efficacy of pegvisomant in patients with acromegaly resistant to somatostatin analogs included six and seven patients only; data were limited to IGF-I levels only; and, in one study (20), results were available only after a very short period (6-12 weeks) of treatment. All the 13 patients achieved normalization of IGF-I levels, and no side effects were noted. Among our 16 patients, of whom 12 were treated for 12 months with pegvisomant, $11 / 14$ in whom the doses could be titrated according to the protocol $(75 \%)$ achieved normal IGF-I levels for the age-adjusted range, consistent with previous data (18). Moreover, IGF-I fall was accompanied by improvement of cardiovascular risk markers, such as total/HDL-cholesterol ratio, insulin sensitivity and blood pressure. The decrease in serum IGF-I levels during pegvisomant treatment has been reported to be accompanied by a dose-dependent increase of serum GH levels (18). GH levels rose after 2 weeks of treatment and remained stable thereafter (18). The GH increase during therapy has raised concerns about potential tumor regrowth. Increase in tumor volume occurred in two of 131 patients during the long-term follow-up, although in both of these cases no clear association between tumor growth and treatment was found (18). GH levels during pegvisomant treatment did not increase significantly in our series of patients. The mechanism for the increase in tumor mass observed in two of our patients remains to be fully clarified: an increase in tumor size after stopping somatostatin analogs is, however, not unexpected and has previously been reported (29-31). In patient no. 6 (shown in Fig. 1), tumor shrinkage was observed during octreotide-LAR, and rebound growth occurred after octreotide-LAR withdrawal; after 6 months of pegvisomant treatment, when IGF-I levels were still not normalized, tumor size was similar to that measured before octreotide-LAR. Even in patient no. 3 (shown in Fig. 2), tumor regrowth was observed after surgery, tumor size was partially reduced during lanreotide therapy, and post-pegvisomant tumor size was not different from that before lanreotide therapy. Thus, in both our patients, tumor regrowth could be due to withdrawal from somatostatin analog treatment. Neither of the two patients showing tumor growth during pegvisomant had received irradiation. It should be noted, however, that neither the percent changes of GH levels nor those of IGF-I levels were correlated with the percent changes of tumor volume. Therefore, changes of GH levels are unlikely to predict tumor increase. Since pegvisomant is a modified GH analog, it is essential that GH levels are subjected to a specific assay that excludes the interference of the treatment itself. Recently, Besser et al. (32) reported that significant tumor regrowth occurs in under $10 \%$ of patients cured surgically, and in under $1 \%$ of patients receiving radiotherapy. Similarly, $2.2 \%$ of somatostatin analog-treated tumors continue to grow. Therefore, $1-3 \%$ of GH-secreting pituitary adenomas grow independently of the treatment approach to them.

Few data are available on the effects of pegvisomant on intermediary metabolism. In a recent study (33), patients with elevated or normal IGF-I levels on octreotide-LAR were switched to treatment with pegvisomant for 28 weeks; both groups had improved glucose and hemoglobin (Hb)A1c levels, and the most marked effects were observed in patients with diabetes. In another study, insulin sensitivity measured by the homeostatic model assessment equation was reported to be improved (34). Another recent study also reported a better glucose profile in patients receiving combined treatment with somatostatin analogs and pegvisomant than when receiving somatostatin analogs only (35). The results of the current study confirm the ability of pegvisomant to improve glucose homeostasis and insulin sensitivity. Pegvisomant treatment normalized glucose levels in all six patients who had abnormalities of glucose tolerance at study entry and in whom the diabetes had been difficult to manage during somatostatin analog therapy. We also observed an increase in HDL-cholesterol levels and reduced total/HDL-cholesterol ratio, considered to be an independent risk factor for cardiovascular diseases (24). These data are partially in agreement with a previous study (36) reporting an improvement of lipoprotein metabolism in patients with acromegaly treated with pegvisomant, although previous data noted an increased level of low-density lipoprotein (LDL) and total cholesterol. Even if the effects on lipid profile and glucose tolerance should be investigated in a larger series of patients, the reduction in the total/HDL-cholesterol ratio could be of clinical relevance in patients with acromegaly who are at risk of developing cardiovascular disease, mainly diastolic heart failure (37). The increase in HDL levels is not, however, an unexpected finding since it was also shown with somatostatin analogs or surgery $(38,39)$.

In the current group of patients, there was a trend to improvement in all symptoms except headache. The lack of statistically significant changes may be due to the small cohort; alternatively, it is possible that the previous long-term treatment with somatostatin analogs, even if unsuccessful, reduced soft tissue swelling to a threshold limit and patients could not appreciate further improvements.

As far as tolerability of pegvisomant is concerned, less than $2 \%$ of patients with increased transaminase levels 
have been reported in the literature (18). We found this complication in $2 / 15$ patients $(13.3 \%)$; however, it is important to point out that both our patients with elevated liver transaminases after pegvisomant treatment were positive for hepatitis $\mathrm{C}$ virus, although having normal baseline transaminases. But it is well known that liver transaminases may fluctuate in such patients. These two patients had been treated for a long time with somatostatin analogs and also had gallbladder abnormalities. In one of these patients, liver transaminases decreased despite increasing the dose of pegvisomant; thus, we can conclude that only in one of our 16 patients did the increase in liver enzymes prevent dose titration and thus the ability to adhere to the protocol. We also found a significant increase of albumin levels after treatment, indicating a preserved secretory liver function. In any case, liver function should be monitored, as recommended in the package insert of the registered indications.

In conclusion, this study reports that 12-month pegvisomant treatment in patients with persistent acromegaly after surgery and resistance to long-term, high-dose treatment with long-acting somatostatin analogs normalizes IGF-I and controls hemodynamic and metabolic complications in the majority of patients, with overall good tolerance of the drug.

\section{Acknowledgement}

This research was a clinical trial supported by Pfizer.

\section{References}

1 Colao A \& Lombardi G. Growth hormone and prolactin excess. Lancet 1998352 1455-1461.

2 Abosch A, Tyrrell JB, Lamborn KR, Hannegan LT, Applebury CB \& Wilson CB. Transsphenoidal microsurgery for growth hormone-secreting pituitary adenomas: initial outcome and longterm results. Journal of Clinical Endocrinology and Metabolism 199883 3411-3418.

3 Lissett CA, Peacey SR, Laing I, Tetlow L, Davis JRE \& Shalet SM. The outcome of surgery for acromegaly: the need for a specialist pituitary surgeon for all types of growth hormone (GH) secreting adenoma. Clinical Endocrinology (Oxford) 199849 653-657.

4 Kreutzer J, Vance ML, Lopes MB \& Laws ER Jr. Surgical management of GH-secreting pituitary adenomas: an outcome study using modern remission criteria. Journal of Clinical Endocrinology and Metabolism 200186 4072-4077.

5 Sheaves R, Jenkins P, Blackburn P, Huneidi AH, Afshar F, Medbak S, Grossman AB, Besser GM \& Wass JA. Outcome of transsphenoidal surgery for acromegaly using strict criteria for surgical cure. Clinical Endocrinology (Oxford) 199645 407-413.

6 Ferone D, Colao A, van der Lely A-J \& Lamberts SWJ. Pharmacotherapy or surgery as primary treatment for acromegaly? Drugs and Aging 200017 81-92.

7 Wass JAH. Evidence for the effectiveness of radiotherapy in the treatment of acromegaly. Journal of Endocrinology $1997 \mathbf{1 5 5}$ (Suppl 1) S57-S55.

8 Stewart PM, Kane FK, Stewart SE, Lancranjan I \& Sheppard MC. Depot long-acting somatostatin analog (Sandostatin ${ }^{\circledR}$ LAR $\left.{ }^{\circledR}\right)$ is an effective treatment for acromegaly. Journal of Clinical Endocrinology and Metabolism 199580 3267-3272.
9 Giusti M, Gussoni G, Cuttica CM Giordano G \& Italian Multicenter Slow Release Lanreotide Study Group. Effectiveness and tolerability of slow release lanreotide treatment in active acromegaly: sixmonth report on an Italian multicenter study. Journal of Clinical Endocrinology and Metabolism 199681 2089-2097.

10 Fløgstad AK, Halse J, Bakke S, Lancranjan I, Marbach P, Bruns C \& Jervell J. Sandostatin ${ }^{\circledR}$ LAR ${ }^{\circledR}$ in acromegalic patients: longterm treatment. Journal of Clinical Endocrinology and Metabolism 199782 23-28.

11 Caron P, Morange-Ramos I, Cogne M \& Jaquet P. Three years follow-up of acromegalic patients treated with intramuscular slow-release lanreotide. Journal of Clinical Endocrinology and Metabolism 199782 18-22.

12 Lancranjan I, Atkinson AB \& the Sandostatin ${ }^{\circledR}$ LAR ${ }^{\circledR}$ group. Results of a European multicenter study with Sandostatin ${ }^{\circledR}$ LAR $®$ in acromegalic patients. Pituitary 19991 105-114.

13 Baldelli R, Colao A, Razzore P, Jaffrain-Rea ML, Marzullo P, Ciccarelli E, Ferretti E, Ferone D, Gaia D, Camanni F, Lombardi G \& Tamburrano G. Two-year follow-up of acromegalic patients treated with SR-lanreotide $30 \mathrm{mg}$. Journal of Clinical Endocrinology and Metabolism 200085 4099-4103.

14 Lundin P, Eden Engstrom B, Karlsson FA \& Burman P. Long-term octreotide therapy in growth hormone-secreting pituitary adenomas: evaluation with serial MR. American Journal of Neuroradiology $199718765-772$.

15 Colao A, Ferone D, Marzullo P, Cappabianca P, Cirillo S, Boerlin V, Lancranjan I \& Lombardi G. Long-term effects of depot longacting somatostatin analog octreotide on hormone levels and tumor mass in acromegaly. Journal of Clinical Endocrinology and Metabolism $2001862779-2786$.

16 Bevan JS, Atkin SL, Atkinson AB, Bouloux PM, Hanna F, Harris PE, James RA, McConnell M, Roberts GA, Scanlon MF, Stewart PM, Teasdale E, Turner HE, Wass JA \& Wardlaw JM. Primary medical therapy for acromegaly: an open, prospective, multicenter study of the effects of subcutaneous and intramuscular slow-release octreotide on growth hormone, insulin-like growth factor-I, and tumor size. Journal of Clinical Endocrinology and Metabolism 2002 $874554-4563$.

17 Melmed S, Sternberg R, Cook D, Klibanski A, Chanson P, Bonert V, Vance M-L, Rhew D, Kleinberg D \& Barkan A. A critical analysis of pituitary tumor shrinkage during primary medical therapy in acromegaly. Journal of Clinical Endocrinology and Metabolism $2005904405-4410$.

18 Trainer PJ, Drake WM, Katznelson L, Freda PU, Herman-Bonert V, van der Lely AJ, Dimaraki EV, Stewart PM, Friend KE, Vance ML, Besser GM, Scarlett JA, Thorner MO, Parkinson C, Klibanski A, Powell JS, Barkan AL, Sheppard MC, Malsonado M, Rose DR, Clemmons DR, Johannsson G, Bengtsson BA, Stavrou S, Kleinberg DL, Cook DM, Phillips LS, Bidlingmaier M, Strasburger CJ, Hackett S, Zib K, Bennett WF \& Davis RJ. Treatment of acromegaly with the growth hormone-receptor antagonist pegvisomant. New England Journal of Medicine 2000342 $1171-1177$.

19 van der Lely AJ, Hutson RK, Trainer PJ, Besser GM, Barkan AL, Katznelson L, Klibanski A, Herman-Bonert V, Melmed S, Vance ML, Freda PU, Stewart PM, Friend KE, Clemmons DR, Johannsson G, Stavrou S, Cook DM, Phillips LS, Strasburger CJ, Hackett S, Zib KA, Davis RJ, Scarlett JA \& Thorner MO. Long term treatment of acromegaly with pegvisomant, a growth hormone antagonist. Lancet 2001358 1754-1759.

20 Herman-Bonert VS, Zib K, Scarlett JA \& Melmed S. Growth hormone receptor antagonist therapy in acromegalic patients resistant to somatostatin analogs. Journal of Clinical Endocrinology and Metabolism 200085 2958-2961.

21 Drake WM, Parkinson C, Akker SA, Monson JP, Besser GM \& Trainer PJ. Successful treatment of resistant acromegaly with a growth hormone receptor antagonist. European Journal of Endocrinology $2001145451-458$.

22 Hypertension control. Report of a WHO expert committee. WHO Technical Report Series 1996862 1-83. 
23 The DECODE study group on behalf of the European Diabetes Epidemiology Group. Glucose tolerance and mortality: comparison of WHO and American Diabetes Association diagnostic criteria. Lancet $1999354617-621$.

24 Castelli WP. Lipid, risk factors and ischaemic heart disease. Atherosclerosis 1996124 (Suppl) S1-S9.

25 Matthews DR, Hosker JP, Rudenski AS, Naylor BA, Treacher DF \& Turner RC. Homeostasis model assessment: insulin resistance and $\beta$-cell function from fasting plasma glucose and insulin concentrations in man. Diabetologia $1985 \mathbf{2 8} 412-419$.

26 Brabant G, von zur Muhlen A, Wuster C, Ranke MB, Kratzsch J, Kiess W, Ketelslegers JM, Wilhelmsen L, Hulthen L, Saller B, Mattsson A, Wilde J, Schemer R. Kann P \& German KIMS Board. Serum insulin-like growth factor I reference values for an automated chemiluminescence immunoassay system: results from a multicenter study. Hormone Research 200360 53-60.

27 Kopchick JJ, Parkinson C, Stevens EC \& Trainer PJ. Growth hormone receptor antagonist: discovery, development and use in patients with acromegaly. Endocrine Review 200223 623-646.

28 Feenstra J, de Herder WW, ten Have SMTH, van den Beld AW, Feelders RA, Janssen JALJM \& van der Lely AJ. Combined therapy with somatostatin analogues and weekly pegvisomant in active acromegaly. Lancet $20053651644-1646$.

29 Barakat S \& Melmed S. Reversible shrinkage of a growth hormone-secreting pituitary adenoma by a long-acting somatostatin analogue, octreotide. Archives of Internal Medicine 1989149 $1443-1445$.

30 Arosio M, Macchelli S, Rossi CM, Casati G, Biella O Faglia G \& Italian Multicenter Octreotide Study Group. Effects of treatment with octreotide in acromegalic patients - a multicenter Italian study. European Journal of Endocrinology 1995133 430-439.

31 Ezzat S, Snyder PJ, Young WF, Boyajy LD, Newman C, Klibanski A, Molitch ME, Boyd AE, Sheeler L, Cook DM, Malarkey WB, Jackson I, Vance ML, Thorner MO, Barkan A, Frohman LA \& Melmed S. Octreotide treatment of acromegaly. A randomized, multicenter study. Annals of Internal Medicine 1992117 711-718.

32 Besser GM, Burman P \& Daly AF. Predictors and rates of treatment-resistant tumor growth in acromegaly. European Journal of Endocrinology 2005153 187-193.
33 Barkan AL, Burman P, Clemmons DR, Drake WM, Gagel RF, Harris PE, Trainer PJ, van der Lely AJ \& Vance ML. Glucose homeostasis and safety in patients with acromegaly converted from long-acting octreotide to pegvisomant. Journal of Clinical Endocrinology and Metabolism 200590 5684-5691.

34 Drake WM, Rowles SV, Roberts ME, Fode FK, Besser GM, Monson JP \& Trainer PJ. Insulin sensitivity and glucose tolerance improve in patients with acromegaly converted from depot octreotide to pegvisomant. European Journal of Endocrinology 2003149 $521-527$.

35 Jørgensen JOL, Feldt-Rasmussen U, Frystyk J, Chen JW, Kristensen LO, Hagen C \& Ørskov H. Cotreatment of acromegaly with a somatostatin analogue and a growth hormone receptor antagonist. Journal of Clinical Endocrinology and Metabolism 2005 $905627-5631$.

36 Parkinson C, Drake WM, Wiersinga G, Besser GM \& Trainer PJ. Serum lipoprotein changes following IGF-I normalization using a growth hormone receptor antagonist. Clinical Endocrinology (Oxford) 200256 303-312.

37 Colao A, Ferone D, Marzullo P \& Lombardi G. Systemic complications of acromegaly: epidemiology, pathogenesis, and management. Endocrine Reviews 200425 102-152.

38 Colao A, Marzullo P \& Lombardi G. Effect of a six-month treatment with lanreotide on cardiovascular risk factors and arterial intima-media thickness in patients with acromegaly. European Journal of Endocrinology 2002146 303-309.

39 Ronchi CL, Varca V, Beck-Peccoz P, Orsi E, Donadio F, Baccarelli A, Giavoli C, Ferrante E, Lania A, Spada A \& Arosio M. Comparison between six-year therapy with long acting somatostatin analogs and successful surgery in acromegaly: effects on cardiovascular risk factors. Journal of Clinical Endocrinology and Metabolism $200691121-128$

Received 18 October 2005

Accepted 22 December 2005 